\title{
Alternative hypotheses related to Alzheimer's disease
}

\author{
Cubinkova $\mathrm{V}^{1,2}$, Valachova $\mathrm{B}^{1,2}$, Uhrinova $\mathrm{I}^{1,2}$, Brezovakova $\mathrm{V}^{1}$, Smolek $\mathrm{T}^{1,2}$, Jadhav $\mathrm{S}^{1,2}$, Zilka $\mathrm{N}^{1,2}$ \\ Institute of Neuroimmunology, Slovak Academy of Sciences, Dubravska 9, 84510 Bratislava, Slovakia. \\ norbert.zilka@savba.sk
}

\begin{abstract}
Alzheimer's disease represents the most common form of dementia and belongs to the group of neurodegenerative disorders characterized by progressive loss of neurons in the central nervous system. In the pathogenesis of Alzheimer's disease several etiologic and pathogenic factors exist, which lead to the dysfunction of neurotransmitter systems and consequent cognitive decline. Last three decades have delivered a crucial progress leading to better understanding of Alzheimer's disease, however, the exact mechanisms of pathology remain unclear. In this review, we summarize some hypotheses such as amyloid and tau hypotheses, inflammatory processes, prion-like hypothesis, the hypothesis of oxidative stress, vascular and cholesterol hypothesis, the hypothesis of metal accumulation in the brain, cell cycle hypothesis, the hypothesis of impaired insulin signalization and another, which were proposed to explain the pathogenesis of this severe disorder (Ref. 115). Text in PDF www.elis.sk. KEY WORDS: Alzheimer's disease, hypothesis, tau protein, amyloid $\beta$.
\end{abstract}

\section{Introduction}

Alzheimer's disease (AD) represents the most common form of dementia and belongs to the group of neurodegenerative disorders characterized by progressive loss of neurons in the central nervous system $(1,2)$. The main risk factor of sporadic AD is age. Above the age of 65 years, incidence of dementia increases exponentially (3). Recently it has been suggested that about 50 million people worldwide suffer from $\operatorname{AD}(4,5,6)$.

Similarly to other age-related diseases (e.g. cardiovascular diseases, diabetes, cancer), it is suggested that several risk factors including environmental, behavioral and diets participate in the pathogenesis of AD. Epidemiologic findings have shown that a lower level of education, previous head trauma, consumption of high-calorie food and sedentary lifestyle can increase the risk of developing of $\mathrm{AD}$, as well. Other risk factors include a positive family history of dementia, genetics factors (e.g. allele 4 of apolipoprotein E), female sex and vascular diseases. Mutation are responsible for less than $1 \%$ of total AD cases (7). Regardless of various genetic causes, all $\mathrm{AD}$ patients show common cognitive impairment and pathological lesions in the brain indicating a common final pathological pathway with different access avenues. Identification of these alternative approaches can help to understand the pathogenesis of $\mathrm{AD}$ and show appropriate treatment strategies $(8,9,10)$.

${ }^{1}$ Institute of Neuroimmunology, Slovak Academy of Sciences, Bratislava, Slovakia, and ${ }^{2}$ Axon Neuroscience R \& D Services SE, Bratislava, Slovakia

Address for correspondence: N. Zilka, Institute of Neuroimmunology, Slovak Academy of Sciences, Dubravska cesta 9, SK-845 10 Bratislava, Slovakia.

Phone: +412.2 .54788100 , Fax: +412.2 .54774276$

Acknowledgements: This work was supported by EU structural funds ITMS 26240220008 and Axon Neuroscience R\&D Services SE.
In the pathogenesis of AD several etiologic and pathogenic factors exist, such as altered calcium homeostasis, genetic factors, hormonal factors, inflammatory or immune factors, vascular dysfunction and dysregulation of cell cycle, which lead to dysfunctions of neurotransmitters systems and consequent cognitive decline $(11,12,13)$.

Pathogenesis of Alzheimer's disease

In the last three decades, extensive progress in the research of AD let to new findings:

- The main pathological components of the disease are accumulation of amyloid $\beta$ and hyperphosphorylated tau protein $(14,15,16)$.

- Amyloid $\beta$ is the product of APP processing, APP gene is localized on chromosome 21 (17).

- AD-like pathological changes are found in the adult brain with trisomy 21 (Down syndrome) (18).

- Increased number of individuals with AD is found in several families indicating autosomal dominant heritability of familiar forms of AD (18).

- Mutations in the three different genes are sufficient for development of familiar form of AD (APP, PSEN1, and PSEN2) (19).

- Allele 4 of apoliprotein E represents the primary risk factor for the common form of $\operatorname{AD}(20,21,22)$.

- Mutation in the tau gene were found to cause frontotemporal dementia (FTD) (23).

The most discussed hypotheses attempt to explain the pathogenesis of $\mathrm{AD}$ via amyloid and tau accumulation, inflammatory processes, oxidative stress, vascular lesions, cholesterol, metal accumulation in the brain, cell cycle disruption and impaired insulin signalization (24). The amyloid cascade was originally proposed more then 20 years ago. This hypothesis suggests that amyloid 
plaques are composed of amyloid aggregates $(25,26)$. However, recent data do not fully support this hypothesis, which localizes amyloid plaques into the centrum of $\mathrm{AD}$ pathology, as it was shown that deposits of amyloid do not correlate with the impairment in cognitive functions. On the other hand, several independent studies demonstrate a close relationship between hyperphosphorylated tau and neurofibrillary tangles and synaptic neuronal loss to memory deficit and cognitive decline (27). Neurodegenerative processes related to tau are necessary for clinical symptoms of AD and are entirely sufficient to cause neurodegeneration in tauopathies where amyloid plaques are absent $(28,29)$. In spite of significant scientific progress in these two hypotheses, further studies are needed to clarify the relationship between amyloid plaques, neurofibrillary tangles and cognitive decline in $\mathrm{AD}$.

In this review, we summarize other hypotheses, which attempt to explain neurodegenerative processes observed in $\mathrm{AD}$.

\section{$\alpha$-synuclein as a pathogenic modulator in AD}

$\alpha$-synuclein is a generally expressed neuronal protein and the primary component of Lewy bodies. Aggregates of this protein are found in a group of neurodegenerative disorders named $\alpha$-synucleinopathies, which include Parkinson's disease. In approximately half of the brains of AD patients $\alpha$-synuclein aggregates were found, mostly restricted to the amygdala $(30,31)$. It was found that levels of soluble $\alpha$-synuclein are about two fold higher in the brains of $\mathrm{AD}$ patients than in control brains and correlate better with cognitive impairment when compare to soluble $A \beta$ and tau (32). Moreover, exaggerated expression of $\alpha$-synuclein in a mouse model induces memory impairment comparable to deficit found in mouse models of AD. Some experimental data signalize that $\mathrm{Ab}$, tau and a-synuclein might synergistically interact and potentiatie mutual accumulation (33).

Even if the role of $\alpha$-synuclein in pathology is unclear, it was found that a doubling of $\alpha$-synuclein levels in neurons in vitro slow down the movement of vesicles between presynaptic endings and reduces the level of neurotransmitters that might be released from the synapse. These changes might impair synaptic transmission $(34,35)$.

\section{The role of inflammation}

Over the last decades a plenty of data were obtained, which support the notion that the neurodegenerative process appearing in $\mathrm{AD}$, involves a strong interaction of the immune cells of the Central Nervous System, primarily microglia (36). The major players of inflammatory pathways are microglia and astrocytes. Molecules involved in the inflammatory process include the neuronal subtype of nicotine receptors, classic and alternative complement pathways, peroxisome proliferators' activating receptors, cytokines and chemokines and to a lesser extent also neurons $(37,38,39)$.

Aggregated amyloid $\beta$ deposits seem to potentiate activation of microglia expressing major histocompatibility complex II and increase secretion of pro-inflammatory cytokines and chemokines $(40,41,42)$. Recently published data showed controversial results regarding the role of the microglia in the nervous system. The question, whether microglia should be considered a friend or foe and whether neuroinflammation is a cause or a consequence of processes accompanying $\mathrm{AD}$, needs to be answered for further explanation of the role of inflammation in Alzheimer's pathological pathways $(42,43)$.

\section{Synaptic pathology: is it a cause or a consequence in AD?}

The synaptic hypothesis suggests that AD is a synaptic disease $(44,45)$. It has been shown that synaptic impairment is an early event in neurodegenerative processes during $\mathrm{AD}$ (46) and that synaptic loss and failure corresponds with cognitive decline in $\mathrm{AD}$ as well $(47,48)$. Although synaptic impairment is an early event, synaptic damage also progresses over the course of the disease. Several factors such as a selective degradation of proteins, abnormal function of synaptic proteins, decreased mRNA levels, etc. were identified as a potential causes leading to the changes in the synapses of AD brains $(49,50,51)$. In addition, synaptic loss was observed parallel to amyloid and tau pathology (52). Recently it was shown that impaired synapses from AD brains released tau protein in response to $\mathrm{KCl}$ stimulation (53). This in-turn may be involved in the progression of tau pathology in the brain. This concept has been intensely investigated in recent years $(54,55)$. On the other hand, it is also suggested that tau can be a perpetrator of synaptic impairment in $\mathrm{AD}$ and other tauopathies, reviewed earlier (56). However, studies also show that hippocampal synaptic loss in $\mathrm{AD}$ does not correlate with Braak stages and represent an early stage in the disease progression, possibly associated with early tau modifications (44). Therefore, the relationship between these two paradigms is still debated.

\section{The role of the reactive oxygen species and oxidative stress}

Overproduction of free radicals leads to neuronal oxidative stress, a condition connected with AD pathogenesis. Oxidative modifications of all biomacromolecules were described in relation to susceptible neurons in AD. It seems that oxidative stress is present in early stages of $\operatorname{AD}(57,58,59,60)$.

It is suggested that oxidative stress in the brains of $\mathrm{AD}$ patients is relatively independent of plaques. The level of oxidative stress is in reality lower in regions containing plaques compared to regions without plaques. One potential explanation is that production of $A \beta$ might be a compensatory response to increased oxidative stress $(61,62)$.

Reactive oxygen species that are generated mainly as byproducts of electron transport chain in mitochondria might induce oxidative damage of cells and cells death. Mitochondrial oxidative phosphorylation is the main source of free radicals, including hydrogen peroxide, hydroxide radicals, and superoxide radical. Consequent oxidative damage is present in lipids, proteins, nucleic acids, and carbohydrates, molecules essential for structural and functional integrity of neurons $(63,64,65)$.

Formation of $A \beta$ oligomers in rat's neurons in vitro produces hydrogen peroxide and hydroxyl radicals that consequently in- 
duce lipids peroxidation in plasma membrane of neurons and glial cells and impairs functions of ATP-ases and glucose transporters leading to alteration of homeostasis of cell calcium and energy metabolism as well as alteration of synaptic functions $(66,67)$.

\section{The vascular hypothesis}

The vascular hypothesis was postulated in 1993 by de la Torre and Mussivand, proposing that abnormal angiogenesis plays a role in $\mathrm{AD}$ pathogenesis (68). Neovascularization in the brain of $\mathrm{AD}$ patients develops as a consequence of altered cerebral perfusion (oligemia) and vessel damage (inflammation). Morphological and biochemical data supporting this assumption include regional increase of capillary density, formation of vascular loops, formation of glommeruloids and expression of angiogenic factors (e.g. vascular endothelial growth factor (VEGF), transforming growth factor $\beta$ (TGF $\beta$ ), and tumor necrosis factor $\alpha$ (TNF $\alpha$ ). It is suggested, that angiogenic activation of the endothelium in grant the AD brain leads to accumulation of $A \beta$ plaques and secretion of neurotoxic peptide, which selectively kills cortical neurons $(69,70,71,72)$.

Thrombogenic regions developing in the vessel walls lead to intravascular accumulation of thrombin. Thrombin activates endothelial cells that secrete APP via a receptor mediated, protein kinase $\mathrm{C}$ dependent pathway. Progressive deposition of APP leads to accumulation of $A \beta$ plaques that induce production of reactive oxygen species inducing further endothelial damage. Accumulated thrombin stimulates angiogenesis and production of APP. This cycle of events depending on the endothelium contributes to the accumulation of $\mathrm{A} \beta$ in brains of $\mathrm{AD}$ patients and leads to neuronal loss $(73,74)$.

\section{Alteration of blood-brain barrier (BBB) permeability}

Above mentioned vascular abnormalities found in AD contribute to alterations of BBB permeability. Since, an intact BBB is essential for prevention of infiltration of toxic products into the brain, impairing BBB permeability leads to accumulation of toxic products and subsequent synaptic and neuronal dysfunction (75, 76). It has been shown that $A \beta$ peptides, tau, $\alpha$-synuclein and prion protein can cross the blood-brain barrier and contribute to induction of disease $(77,78)$. BBB represents the connection between neural and circulating cells of the immune system, thus plays a key part in the generation and upkeep of chronic inflammation during AD. Further studies are needed to fully elucidate the mechanisms that regulate $\mathrm{BBB}$ collapse in connection to chronic neuroinflammation in $\mathrm{AD}$ (79).

\section{Cholesterol as a causative factor in Alzheimer disease}

Apolipoprotein E (ApoE) represents one of the main apolipoproteins in plasma and the main transporter of cholesterol in the brain. In humans three alleles of ApoE gene are known: $\varepsilon 2, \varepsilon 3$ a $\varepsilon 4$. A plenty of independent studies have shown that the ApoE $\varepsilon 4$ allele is associated with an increased risk for $\mathrm{AD}$, while $\mathrm{ApoE}$ $\varepsilon 2$ seems to bestow protection $(80,8182)$. However, ApoE $\varepsilon 4$ is neither necessary nor able to cause AD, only increases the risk of developing the disease. In vitro and in vivo studies confirmed an $\mathrm{A} \beta$-independent role for ApoE which may force neuroinflammation, induce impairment of synaptic plasticity and modify the response to neuronal injury (83).

Exact mechanisms that enable ApoE to participate on AD have yet to be elucidated. Recent data proved the role of ApoE4 as a specific mediator of neuroinflammation, suggesting that faulty ApoE4 function modulates $A \beta$ induced effects on inflammatory receptor signaling (84). Another role of ApoE is in neuronal signalization, participation on conservation of integrity of blood-brain-barrier and in regulation of cholinergic neurotransmission $(85,86)$.

Nevertheless, the most important function of ApoE is its role as mediator in $A \beta$ metabolism. It was hypothesized that $A p o E$ may induce pathological $\beta$-sheet conformational changes in $A \beta$ (87). ApoE binds $A \beta$, influences accumulation and clearance of $A \beta$ and is necessary for accumulation of amyloid. Moreover, ApoE influences deposition of amyloid in relation to particular ApoE allele $(86,88)$.

The role of cholesterol in AD support the fact that intracellular cholesterol might regulate processing of APP via direct modulation of secretase activity or via modulation of intracellular transfer of secretases or APP. Increased concentration of cholesterol potentiates activity of $\gamma$-secretase and the activity of amyloidogenic pathway, whereas reduced cholesterol levels promote the non-amyloidogenic pathway. There exist several genetic factors that create connection between metabolism of cholesterol and $\mathrm{AD}$, however only for the ApoE gene the relationship was proven $(89,90)$. However, contradictory data from different researches have made it difficult to characterize whether the ApoE $\varepsilon 4$ allele undergoes a gain of toxic function, neuroprotective function loss, or both (91).

\section{Hypothesis of metal accumulation in the brain}

It is suggested that endogenous biometals such as copper, iron, zinc and exogenous metals as aluminum might represent factors or cofactors in $\mathrm{AD}$ pathogenesis. Pro-active role of metal ions in stimulation of $A \beta$ aggregation and their interaction with $A \beta$ are relatively well described in in vitro conditions. Majority of glutamatergic synapses in cerebral cortex release zinc together with glutamate. Zinc ions induce fast precipitation of $A \beta$ and have the ability to form protease-resistant unstructured aggregates. Moreover, studies using animal models have shown that genetic ablation of synaptic zinc significantly reduced the quality of amyloid plaques $(92,93,94)$.

Copper is released from synapses and acts as potential mediator of $A \beta$ aggregation in conditions of mild acidosis. Moreover, copper and iron might interact with $A \beta$ as catalysts for generation of hydrogen peroxide via reduction processes utilizing oxygen and enable reduction of compounds such as cholesterol, vitamin $\mathrm{C}$, and catecholamine $(95,96)$.

In relation to AD-related dyshomeostasis of metals is the role of altered metabolism of aluminum interesting but controversial. Even if aluminum is related to specific neurologic injuries, con- 
nection between aluminum and AD-like pathology was not proven. The role of aluminum in $\mathrm{AD}$ pathology remains unclear $(97,98)$.

\section{Hypothesis of impaired insulin signalization}

Abnormal function of insulin and axis of insulin-like growth factors I (IGF-I) might constitute another potential mechanism participating in the development of AD. Similarly to insulin, IGF-1 also stimulates the release of $A \beta$ from neurons and exerts a stimulatory effect on clearance of amyloid from the brain (86). Moreover, the levels of insulin and IGF-1 are altered in AD patients, while sensitivity of cells to insulin and IGF-1 is probably reduced in these patients. Insulin exerts a twofold effect on brain's $A \beta$. On the one side insulin stimulates neuronal release of $A \beta$, on the other side it participate on extraneuronal accumulation of $A \beta$ via competition with insulin-degrading enzymes. Insulin results in an increase of $A \beta$ in the brain. IGF-1 reduces levels of $A \beta$ in the brain and increases levels of plasma $\mathrm{A} \beta$ bound to transport proteins. Therefore, IGF-1 stimulates clearance of A $\beta$ from the brains (99, 100). Progressive loss of sensitivity to IGF-1 and consequently to insulin leads to accumulation of $A \beta$ in the brain. Initial reduction of sensitivity to plasma IGF-1 in regions of the blood-brain-barrier leads to reduced clearance of $A \beta$ and therefore to accumulation of $A \beta$ in the brain. Increased levels of $A \beta$ prevent binding of insulin and IGF-1 to their receptors and thus induce resistance to insulin/ IGF-1 in neurons. In response to this resistance, homeostatic compensatory mechanisms are activated. These mechanisms increase levels of insulin/IGF-1 to maintain functions of target cells. High concentrations of insulin reduce ability of IDE (insulin degrading enzyme) to eliminate $A \beta$, which leads to $A \beta$ accumulation and activation of a self-perpetuating vicious circuit $(101,102)$.

\section{Cell cycle hypothesis}

A body of data indicates an important role of altered cell cycle in AD pathogenesis. The cell cycle is regulated by a complex mechanism of feedback with many control points. Neurons in the hippocampus of adult individuals are in majority in a non-dividing phases, named G0. If they reach this phase, cells become terminally differentiated; it means that they are not able to re-enter the cell cycle. However, this process is altered in vulnerable neurons. Data indicate that cells in the G0 phase that are not mitotically active, are erroneously reactivated in $\mathrm{AD}$ and therefore forced into the cell cycle, however, these cells are not able to complete the cell cycle. Moreover, these differentiated cells do not undergo mitosis because they have reduced ability to do so. Therefore these cells undergo death via apoptosis $(103,104)$.

It seems that there exist both a direct and indirect relationship between oxidative stress and abnormalities of cell cycle. This assumption creates the basis for a two-hit hypothesis, suggesting that neurodegeneration in $\mathrm{AD}$ develops as a consequence of oxidative stress and altered cell cycle. The effect of these two hits induces a detrimental cycle of oxidative stress, inflammation, aggregation of $\mathrm{A} \beta$ and tau, mitotic dysfunction, and cell death. These processes are involved in development of $\mathrm{AD}$ (105).

\section{Hypotheses related to the role of neurotransmitters in Al- zheimer's disease}

$\mathrm{AD}$ is characterized by degenerative changes in various neurotransmitters systems, including the cholinergic, glutamatergic, noradrenergic and serotoninergic system, and several systems utilizing neuropeptides. Cognitive changes in $\mathrm{AD}$ patients are the result of cholinergic and glutamatergic neurons, as well as altered function of surviving neurons in these two systems (106).

Alteration of cholinergic neurons in AD patients participates in cognitive and behavioral symptoms characteristic for this disease. This hypothesis is based on assumption that selective loss of cholinergic neurotransmission in cerebral cortex and hippocampus is the prime cause of cognitive dysfunction. Even if several different biochemical changes were found in $\mathrm{AD}$ brains, impairment of cholinergic functions is the most consistent finding and extent of cholinergic system impairment closely correlates with severity of the disease (107). Moreover, it is well known that anticholinergic drugs (e.g. atropine, scopolamine) impair intellectual abilities in normal individuals as well as in AD patients (108). Impairment of cortical cholinergic neurotransmission participates ion pathology of $A \beta$ and increases phosphorylation of tau protein (107),

Glutamate is the main excitatory neurotransmitter in the brain. It seems that glutamate receptors play a central role in impairment of synapses induced by $A \beta$ oligomers. $A \beta$ oligomers bound on neurons alter the activity as well as number of NMDA (Nmethyl-D-aspartate) and AMPA 2-amino-3- (3-hydroxy-5-methylisoxazol-4-yl) propanoic acid) subtypes of glutamatergic neurons in membranes with consequent impairment of signal pathways participating on synaptic plasticity (109).

\section{Prion-like hypothesis}

Experimental evidence in recent years demonstrates that misfolded proteins involved in neurodegeneration such as tau, amyloid $\beta$ or $\alpha$-synuclein are able to be transmitted from cell to cell, this phenomenon is called prion-like transmission $(110,111,112)$. Already in 1991, Braak and Braak showed that tau protein spreads from the entorhinal cortex to the hippocampal region and then reaches the isocortical areas (113). In the last decade, several independent studies support the idea of prion-like spreading of tau pathology and they have uncovered some mechanisms which regulate this process $(114,115)$.

\section{Conclusion}

In summary, several hypotheses have been suggested in effort to explain the pathogenesis of Alzheimer's disease. Some of them were mentioned in this review, such as amyloid and tau hypotheses, inflammation, vascular hypothesis, oxidative stress, cell cycle hypothesis and others. A plethora of independent studies support these hypotheses and their role in Alzheimer's pathogenesis, however, none of them is able to exactly explain the mechanism leading to Alzheimer's disease. Therefore, further investigation is needed to better understand all the processes behind Alzheimer's disease. 
$210-216$

\section{References}

1. Cummings JL, Zhong K. Treatments for behavioural disorders in neurodegenerative diseases: drug development strategies. Nat Rev Drug Discov 2006; 5 (1): 64-74.

2. Selkoe DJ. Alzheimer's disease. Cold Spring Harb Perspect Biol 2011; 3 (7).

3. Corrada MM et al. Dementia Incidence Continues to Increase with Age in the Oldest Old The 90+ Study. 2015.

4. Kril JJ, Halliday GM. Alzheimer's disease: Its diagnosis and pathogenesis. Internat Rev Neurobiol Acad Press 2001; 48: 167-217.

5. Querfurth HW, LaFerla FM. Alzheimer's disease. N Engl J Med 2010; 362 (4): 329-344.

6. Castellani RJ et al. Alzheimer disease. Dis Mon 2010; 56 (9): 484-546.

7. Thies W, Bleiler L. Alzheimer's disease facts and figures. Alzheimer's Dement 2011; 7: 208-244.

8. Chapman PF, Falinska M, Knevett SG, Ramsay MF. Genes, models and Alzheimer's disease. Trends Genet 2001; 17: 254-261.

9. Holtzman DM, Morris JC, Goate AM. Alzheimer's Disease: The Challenge of the Second Century. Sci Transl Med 2011; 3: 1-35.

10. Lane C, Hardy J, Schott J. Alzheimer's disease. Eur J Neurol 2017.

11. Mattson MP. Oxidative stress, perturbed calcium homeostasis, and immune dysfunction in Alzheimer's disease. J Neuroviral 2002; 8 (6): $539-550$.

12. Uttara B, Singh AV, Zamboni P, Mahajan RT. Oxidative stress and neurodegenerative diseases: a review of upstream and downstream antioxidant therapeutic options. Curr Neuropharmacol 2009; 7: 65-74.

13. Gandhi S, Abramov AY. Mechanism of oxidative stress in neurodegeneration. Oxid Med Cell Longev 2012.

14. Bird TD. Genetic factors in Alzheimer's disease. N Engl J Med 2005; 352 (9): 862-864.

15. Novak M, Jakes R, Edwards PC, Milstein C, Wischik CM. Difference between the tau protein of Alzheimer paired helical filament core and normal tau revealed by epitope analysis of monoclonal antibodies 423 and 7.51. Proc Natl Acad Sci USA 1991; 88 (13): 5837-5841.

16. Novak M, Kabat J, Wischik CM. Molecular characterization of the minimal protease resistant tau unit of the Alzheimer's disease paired helical filament. EMBO J 1993; 12: 365-370.

17. Masters CL et al. Amyloid plaque core protein in Alzheimer disease and Down syndrome. Proc Natl Acad Sci USA 1985; 82 (12): $4245-4249$.

18. Cacace R, Sleegers K, Van Broeckhoven Ch. Molecular genetics of early-onset Alzheimer's disease revisited. Alzheimers Dement 2016; 12 (6): 733-748.

19. Bekris LM et al. Genetics of Alzheimer Disease. J Geriatr Psychiat Neurol 2010; 23 (4): 213-227.

20. Corder EH et al. Gene dose of apolipoprotein E type 4 allele and the risk of Alzheimer's disease in late onset families. Science 1993; 261 : 921-923.

21. Huang Y, Mucke L. Alzheimer mechanisms and therapeutic strategies. Cell 2012; 148 (6): 1204-1222.

22. Liu CH et al. Apolipoprotein E and Alzheimer disease: risk, mechanisms and therapy. Nat Rev Neurol 2013; 9 (2): 106-118.
23. Goedert M, Spillantini MG. Tau mutations in frontotemporal dementia FTDP-17 and their relevance for Alzheimer's disease. Biochim Biophys Acta 2009; 1502 (1): 110-121.

24. Lansbury PT, Lashuel HA. A century-old debate on protein aggregation and neurodegeneration enters the clinic. Nature 2006; 443 (7113): 774-779.

25. Mudher A, Lovestone S. Alzheimer's disease-do tauists and baptists finally shake hands? Trends Neurosci 2002; 25 (1): 22-26.

26. Russo C et al. Molecular aspects of neurodegeneration in Alzheimer's disease. Funct Neurol 2002; 17 (2): 65-70.

27. Giacobini E, Gold G. Alzheimer disease therapy-moving from amyloid-beta to tau. Nat Rev Neurol 2013.

28. Iqbal K, Grundke-Iqbal I. Alzheimer neurofibrillary degeneration: significance, etiopathogenesis, therapeutics and prevention. J Cell Mol Med 2008; 12 (1): 38-55.

29. Castellani RJ, Rolston RK, Smith M. Alzheimer Disease. Dis Mon 2011; 56: 1-60.

30. Bendor J, Logan T, Edwards RH. The Function of $\alpha$-Synuclein. Neuron 2013; 79 (6).

31. KimWS, Kagedal K, Halliday GM. Alpha-synuclein biology in Lewy body diseases. Alzheimers Res Ther 2014; 6 (5): 73.

32. Larson ME et al. Soluble $\alpha$-synuclein is a novel modulator of Alzheimer's disease Pathophysiology. J Neurosci 2012; 32 (30): 10253-10266.

33. Suh YH, Checler F. Amyloid precursor protein, presenilins, and alphasynuclein: molecular pathogenesis and pharmacological applications in Alzheimer's disease. Pharmacol Rev 2002; 54 (3): 469-525.

34. Scott D, Roy S. $\alpha$-Synuclein Inhibits Intersynaptic Vesicle Mobility and Maintains Recycling-Pool Homeostasis. J Neurosci 2012; 32 (30): 10129-10135.

35. Schulz-Schaeffer WJ. The synaptic pathology of $\alpha$-synuclein aggregation in dementia with Lewy bodies, Parkinson's disease and Parkinson's disease dementia.Acta Neuropathol 2010; 120 (2): 131-43.

36. Molteni M, Rossetti C. Neurodegenerative diseases: The immunological perspective. J Neuroimmunol 2017; 313: 109-115.

37. Tuppo EE, Arias HR. The role of inflammation in Alzheimer's disease. Int J Biochem Cell Biol 2005; 37 (2): 289-305.

38. Zilka N, Novak M. The tangled story of Alois Alzheimer. Bratisl Lek Listy 2006; 107 (9-10): 343-345.

39. Zilka $\mathbf{N}$ et al. The self-perpetuating tau truncation circle. Biochem soc Trans 2012; 40 (4): 681-686.

40. Luber-Narod J, Rogers J. Immune system associated antigens expressed by cells of the human central nervous system.Neurosci Lett 1988; 94 (1-2): 17-22.

41. Ballatore $\mathbf{C}$ et al. Tau-mediated neurodegeneration in Alzheimer's disease and related disorders. Nat Rev Neurosci 2007; 8 (9): 663-672.

42. Wyss-Coray T. Inflammation in Alzheimer disease: driving force, bystander or beneficial response? Nat Med 2006; 12 (9): 1005-1015.

43. Wyss-Coray T, Rogers J. Inflammation in Alzheimer Disease - A Brief Review of the Basic Science and Clinical Literature. Cold Spring Harb Perspect Med 2012; 2 (1).

44. Scheff SW, Price DA, Schmitt FA, Mufson EJ. Hippocampal synaptic loss in early Alzheimer's disease and mild cognitive impairment. Neurobiol Aging 2006; 27: 1372-1384. 
45. Selkoe DJ. Alzheimer's disease. Cold Spring Harb Perspect Biol 2011; 3 (7).

46. Masliah $\mathbf{E}$ et al. Three-dimensional analysis of the relationship between synaptic pathology and neuropil threads in Alzheimer disease. J Neuropathol. Exp Neurol 1992; 51: 404-414.

47. Davies CA et al. A quantitative morphometric analysis of the neuronal and synaptic content of the frontal and temporal cortex in patients with Alzheimer's disease. J Neurol Sci 1987; 78: 151-164.

48. Terry RD et al. Physical basis of cognitive alterations in Alzheimer's disease: synapse loss is the major correlate of cognitive impairment. Ann Neurol 1991; 30: 572-580.

49. Callahan LM, Vaules WA, Coleman PD. Quantitative decrease in synaptop,hysin message expression and increase in cathepsin D message expression in Alzheimer disease neurons containing neurofibrillary tangles. J Neuropathol Exp Neurol 1999; 58: 275-287.

50. Gylys KH et al. Synaptic changes in Alzheimer's disease - Increased Amyloid $-\beta$ and gliosis in surviving terminals is accompanied by decreased PSD-95 fluorescence. Am J Pathol 2004; 165: 1809-1817.

51. Louneva $\mathbf{N}$ et al. Caspase-3 Is Enriched in Postsynaptic Densities and Increased in Alzheimer's Disease. Am J Pathol 2008; 173: 1488-1495.

52. Fein JA et al. Co-localization of amyloid beta and tau pathology in Alzheimer's disease synaptosomes. Am J Pathol 2008; 172: 1683-1692.

53. Sokolow $\mathrm{S}$ et al. Pre-synaptic C-terminal truncated tau is released from cortical synapses in Alzheimer's disease. J Neurochem 2015; 133: 368-379.

54. Spires-JonesTL, Hyman BT. The intersection of amyloid beta and tau at synapses in Alzheimer's disease. Neuron 2014; 82 (4): 756-771.

55. Zhou $\mathbf{L}$ et al. Tau association with synaptic vesicles causes presynaptic dysfunction. Nat Commun 2017; 11 (8): 15295.

56. Jadhav S. Tau mediated synaptic damage in Alzheimer's disease. Transl Neurosci 2015; 6 (1): 214-226.

57. Zhu X et al. Oxidative stress signalling in Alzheimer's disease. Brain Res 2004; 100 (1-2): 32-39.

58. Bennett S, Grant MM, Aldred S. Oxidative stress in vascular dementia and Alzheimer's disease: a common pathology. J Alzheimers Dis 2009; 17 (2): 245-257.

59. Cente M, Mandakova S, Filipcik P. Memantine prevents sensitivity to excitotoxic cell death of rat cortical neurons expressing human truncated tau protein. Cell Mol Neurobiol 2009; 29: 945-949.

60. Massaad CA. Neuronal and Vascular Oxidative Stress in Alzheimer's Disease. Curr Neuropharm 2011; 662-673.

61. Nunomura A et al. Oxidative damage is the earliest event in Alzheimer disease. J Neuropathol Exp Neurol 2001; 60 (8): 759-767.

62. Swerdlow RH. Mitochondria and cell bioenergetics: increasingly recognized components and a possible etiologic cause of Alzheimer's disease. Anmtioxid Redox Signal 2012; 16 (12): 1434-1455.

63. Lum H, Roebuck KA. Oxidant stress and endothelial cell dysfunction. Am J Physiol Cell Physiol 2001; 280 (4): C719-741.

64. Zorov DB, Juhaszova M, Sollott SJ. Mitochondrial Reactive Oxygen Species (ROS) and ROS-Induced ROS Release. Physiol Rev 2014; 94 (3): 909-950.

65. Nita M, Grzybowski A. The Role of the Reactive Oxygen Species and Oxidative Stress in the Pathomechanism of the Age-Related Ocular Diseases and Other Pathologies of the Anterior and Posterior Eye Segments in Adults. Oxid Med Cell Longev. 2016.
66. Uttara B et al. Oxidative Stress and Neurodegenerative Diseases: A Review of Upstream and Downstream Antioxidant Therapeutic Options. Curr Neuropharmacol 2009; 7 (1): 65-74.

67. Kapogiannis D, Mattson MP. Disrupted energy metabolism and neuronal circuit dysfunction in cognitive impairment and Alzheimer's disease. Lancet Neurol 2011; 10 (2): 187-198.

68. De la Torre JC, Mussivand T. Can disturbed brain microcirculation cause Alzheimer's disease? Neurol Res 1993; 15: 146-153.

69. Perlmutter LS, Barron E, Chui HC. Morphologic association between microglia and senile plaque amyloid in Alzheimer's disease. Neurosci Lett 1990; 119 (1): 32-36.

70. Tarkowski E. Cytokines in dementias. Curr Drug Targets Inflamm Allergy 2002; 1 (2): 193-200.

71. Grammas $\mathbf{P}$ et al. Vascular signaling abnormalities in Alzheimer's disease. Cleve Clin Med 2011.

72. Kelleher RJ, Soiza RL. Evidence of endothelial dysfunction in the development of Alzheimer's disease: Is Alzheimer's a vascular disorder? Am J Cardiovasc Dis 2013; 3 (4): 197-226.

73. Vagnucci AH, Li WW. Alzheimer's disease and angiogenesis. Lancet 2003; 361 (9357): 605-608.

74. Winkler EA, Sagare AP, Zlokovic BV. The pericyte: a forgotten cell type with important implications for Alzheimer's disease? Brain Pathol 2014; 24 (4): 371-386.

75. Kalaria RN. Cerebral vessels in ageing and Alzheimer's disease. Pharmacol Ther 1996; 72: 193-214.

76. Santos CY et al. Pathophysiologic relationship between Alzheimer's disease, cerebrovascular disease, and cardiovascular risk: A review and synthesis. Alzheimer s Dement (Amst) 2017; 9 (7): 69-87.

77. Sharma HS et al. The blood-brain barrier in Alzheimer's disease: novel therapeutic targets and nanodrug delivery. Int Rev Neurobiol 2012; 102: 47-90.

78. Banks WA et al. Tau Proteins Cross the Blood-Brain Barrier. J Alzheimers Dis 2017; 55 (1): 411-419.

79. Zenaro E, Piacentino G, Constantin G. The blood-brain barrier in Alzheimer's disease. Neurobiol 2017; 107: 41-56.

80. Verghese PB, Castellano JM, Holtzman DM. Apolipoprotein E in Alzheimer's disease and other neurological disorders. Lancet Neurol 2010; 10 (3): 241-252.

81. Liu CH et al. Apolipoprotein E and Alzheimer disease: risk, mechanisms and therapy. Nat Rev Neurol 2013; 9 (2): 106-118.

82. Wood WG et al. Cholesterol as a Causative Factor in Alzheimer Disease: A Debatable Hypothesis. J Neurochem 2014; 129 (4): 559-572.

83. Puglielli L, Tanzi RE, Kovacs DM. Alzheimer's disease: the cholesterol connection. Nat Neurosci 2003; 6 (4): 345-351.

84. Tai LM et al. APOE-modulated $A \beta$ - induced neuroinflammation in Alzheimer's disease: current landscape, novel data and future perspective. J Neurochem 2015; 133 (4): 465-488.

85. Donahue JE, Johanson CE. Apolipoprotein E, amyloid-beta, and blood-brain barrier permeability in Alzheimer disease. J Neuropathol Exp Neurol 2008; 67 (4): 261-270.

86. Mohandas E et al. Neurobiology of Alzheimer's disease. Indian J Psychiatry 2009; 51 (1): 55-61. 
210-216

87. Wisniewski T, Frangione B. Apolipoprotein E: a pathological chaperone protein in patients with cerebral and systemic amyloid. Neurosci Lett 1992; 135: 235-238.

88. Selkoe DJ. Alzheimer's disease is a synaptic failure. Science 2002; 298 (5594): 789-791.

89. Zhang J, Liu Q. Cholesterol metabolism and homeostasis in the brain. Protein Cell 2015; 6 (4): 254-264.

90. Arenas F, Garcia-Ruiz C, Fernandez-Checa JC. Intracellular Cholesterol Trafficking and Impact in Neurodegeneration. Front Mol Neurosci 2017; 10: 382 .

91. Kim J, Jacob MB, Holtzman DM. The Role of Apolipoprotein E in Alzheimer's Disease. Neuron 2009; 63 (3): 287-303.

92. Brown CE, Dyck RH. Distribution of zincergic neurons in the mouse forebrain. J Comp Neurol 2004; 479: 156-167.

93. Takeda A. Zinc signaling in the hippocampus and its relation to pathogenesis of depression. Mol Neurobiol 2011; 44: 166-174.

94. Ayton S, Lei P, Bush AI. Metallostasis in Alzheimer's disease. Free Radic Biol Med 2013; 62: 76-89.

95. Mantyh PW et al. Aluminum, Iron, and Zinc Ions Promote Aggregation of Physiological Concentrations of $\beta$-Amyloid Peptide. J Neurochem 1993.

96. Zatta et al. Alzheimer's disease, metal ions and metal homeostatic therapy. Trend Pharmacol Sci 2009; 30 (7): 346-355.

97. Zatta et al. In vivo and in vitro effects of aluminum on the activity of mouse brain acetylcholinesterase. Brain Res Bull 2002; 59 (1): 41-45.

98. Tomljenovic L. Aluminum and Alzheimer's disease: after a century of controversy, is there a plausible link? J Alzheimers Dis 2010; 23 (4): $567-598$.

99. Bedse G, Domenico FD, Servid G. Aberrant insulin signaling in A1zheimer's disease: current knowledge. Front Neurosci 2015.

100. Gontier G et al. Blocking IGF Signaling in Adult Neurons Alleviates Alzheimer's Disease Pathology through Amyloid- $\beta$ Clearance. J Neurosci 2015; 35 (33): 11500-11533.

101. Bosco D et al. Possible implications of insulin resistance and glucose metabolism in Alzheimer's disease pathogenesis. J Cell Mol Med 2011; 15 (9): 1807-1821.
102. Carro E, Torres-Aleman I. Serum insulin-like growth factor I in brain function. Keio J Med 2006; 55 (2): 59-63.

103. Neve RL, McPhie DL. Dysfunction of Amyloid Precursor Protein Signaling in Neurons Leads to DNA Synthesis and Apoptosis. Biochim Biophys Acta 2007; 172 (4): 430-437.

104. Bonda DJ et al. Oxidative stress in Alzheimer disease: a possibility for prevention. Neuropharmacology 2010; 59 (4-5): 290-294.

105. Zhu X et al. Alzheimer disease, the two-hit hypothesis: an update. Biochim Biophys Acta 2007; 172 (4): 494-502.

106. Weng GL. Neuropathologic changes in Alzheimer's disease. J Clin Psychiatry 2003; 9: 7-10.

107. Ferreira-Vieira TH et al. Alzheimer's disease: Targeting the Cholinergic System. Curr Neuropharmacol 2016; 14 (1): 101-115.

108. Sivaprakasam K. Towards a unifying hypothesis of Alzheimer's disease: cholinergic system linked to plaques, tangles and neuroinflammation. Curr Med Chem 2006;13 (18): 2179-2188.

109. Paula-Lima AC, Brito-Moreira J, Ferreira ST. Deregulation of excitatory neurotransmission underlying synapse failure in Alzheimer's disease. J Neurochem 2013; 126 (2): 191-202.

110. Novak M. Truncated tau protein as a new marker for Alzheimer's disease. Acta Virol 1994; 38: 173-189.

111. Li JY et al. Lewy bodies in grafted neurons in subjects with Parkinson's disease suggest host-to-graft disease propagation. Nat Med 2008; 14 (5): 501-503.

112. Prusiner SB et al. Evidence for $\alpha$-synuclein prions causing multiple system atrophy in humans with parkinsonism. Proc Natl Acad Sci USA 2015; 112 (38).

113. Braak H, Braak E. Alzheimer's disease affects limbic nuclei of the thalamus. Acta Neuropathol 1991; 81: 261-268.

114. Clavaguera $\mathbf{F}$ et al. Brain homogenates from human tauopathies induce tau inclusions in mouse brain. Proc Natl Acad Sci USA 2013; 110: 9535-9540.

115. Clavaguera $\mathbf{F}$ et al. 'Prion-like' templated misfolding in tauopathies. Brain Pathol 2015; 23, 342-349.

Received December 21, 2017. Accepted January 9, 2018. 